TRIBUNAL SUPREMO 



\title{
¿DEBE EXIGIRSE MOTIVACIÓN A LOS ACUERDOS DE CONCESIÓN DE INDULTOS? COMENTARIO A LA SENTENCIA DEL PLENO DE LA SALA DE LO CONTENCIOSO-ADMINISTRATIVO DEL TRIBUNAL SUPREMO DE 20-11-2013
}

\author{
M. ${ }^{a}$ ISABEL SERRANO MAÍlLO \\ Profesora Titular Interina de Derecho Constitucional \\ Universidad Complutense de Madrid
}

\begin{abstract}
SUMARIO
I. Introducción.

II. Sentencia de la Sala del Pleno de lo Contencioso-Administrativo del Tribunal Supremo de 20 de noviembre de 2013.

III. Conclusión.
\end{abstract}

\section{INTRODUCCIÓN}

El indulto es un acto graciable por el cual el Gobierno - al margen del poder judicial- puede conmutar (total o parcialmente) una pena ${ }^{1}$. Así parece desprenderse de la doctrina del TS en esta materia, aunque lo cierto es que la Constitución Española atribuye la competencia para ejercer el derecho de gracia al Rey (art. 62.i): «Corresponde al Rey ejercer el derecho de gracia con arreglo a la ley, que no podrá autorizar indultos generales»). Sea quien fuere el órgano competente ${ }^{2}$, a lo que nos

1 STS de 20 de noviembre de 2013. «La decisión de conceder o denegar un indulto corresponde al Gobierno». En el mismo sentido, PÉREZ FRANCESCH, J. L. y DOMÍNGUEZ GARCÍA, F., «El indulto como acto del gobierno: una perspectiva constitucional», en Revista de Derecho Constitucional, núm. 53, UNED, 2002, p. 32: «El indulto, por tanto, se configura como una decisión del Gobierno y no del Monarca»

2 STS de 2 de diciembre de 2005: «El indulto está previsto en el artículo 62.i) de la Constitución que lo incluye entre las atribuciones del Rey. No obstante, de acuerdo con los principios que informan a la Monarquía parlamentaria, esa potestad no es ejercida materialmente por el Jefe del Estado, sino por el Gobierno que es a quien la Ley a la que se remite ese precepto encomienda adoptar la decisión correspondiente. El ejercicio 
referiremos más adelante, lo cierto es que se trata de una figura controvertida dado que permite al Poder Ejecutivo interferir en las funciones del Poder Judicial, modificando la pena impuesta por un juez o tribunal.

En el antiguo régimen, el titular del derecho de gracia era el Rey, «que por estar... desligado de la fuerza vinculante de las leyes, podía dictar otras nuevas... derogarlas o, simplemente, dispensar de su cumplimiento, así como dejar sin efecto sentencias judiciales condenatorias pronunciadas en aplicación de leyes vigentes... El ámbito del derecho de gracia era amplísimo... Hoy estamos en una posición completamente diferente de aquella... el derecho de gracia ha quedado muy reducido hasta abarcar poco más que la concesión de los indultos singulares» ${ }^{3}$.

Se trata de una figura que parece tener poca justificación en un sistema democrático, además de haber sido objeto de frecuentes abusos por parte de los Gobiernos $^{4}$, algo que ya era evidente a finales del siglo xIx y que queda patente en el preámbulo de la Ley provisional para el ejercicio de la gracia de indulto de 1870 —que sigue en vigor-, donde, refiriéndose a la concesión de indultos, hablaba de la «necesidad cada vez más apremiante hacer de una vez imposibles para siempre estos abusos...» No obstante, es una figura que sigue existiendo en la mayor parte

del derecho de gracia es, pues, una facultad sustancialmente gubernativa». Vid. GARCÍA MAHAMUT, R., El indulto: un análisis jurídico-constitucional. Madrid, Marcial Pons, 2004, p. 24. LAFUENTE BALLE, J. M. ${ }^{a}$, «Comentario al artículo 62.i) de la Constitución, en ALZAGA VILLAAMIL, O. (Dir.) Comentarios a la Constitución Española de 1978. Madrid, EDERSA, tomo V, 1997, pp. 255 y ss.

3 STS de 20 de febrero de 2013: «el indulto particular es un acto del Gobierno que se exterioriza por un real Decreto acordado en Consejo de Ministro, firmado por el Rey, con el referendo del Ministro de Justicia».

4 Recordemos indultos concedidos simultáneamente en el año 2000 ( $A B C$ de 4 de diciembre de 2000: «Entre los 1443 casos, 460 habían sido condenados por deserción del servicio militar, 730 por delitos leves y 278 personas condenadas a penas superiores a los tres años. Los condenados a penas leves han obtenido el indulto total y en el caso de delitos graves el indulto es parcial»). En El País de 9 de diciembre de 2012 (p. 16), bajo el titular: «Los políticos tienen perdón», recoge: «Desde 2000 han sido indultados 226 reos por delitos contra la Administración Pública, 107 malversadores, 25 prevaricadores y 16 por cohecho». BRAGUE CAMAZANO, J. y REVIRIEGO PICÓN, F., «Gobierno en funciones y despacho ordinario de los asuntos públicos (Las SSTS de 20 de septiembre y de 2 de diciembre de 2005)», en Teoría y realidad Constitucional, núm. 18, 2006, recogen: «Volviendo la mirada atrás, resulta indudable que el supuesto más llamativo en esta materia lo constituyó aquel indulto, cuasi general, aprobado por el Consejo de Ministros en su reunión de 1 de diciembre de 2000. En virtud de esta medida de gracia, ampliamente discutida, se llegó a indultar a mil cuatrocientos cuarenta y tres personas, indultos entre los que se contarían los de casi quinientos insumisos al servicio militar obligatorio, así como algunos otros especialmente polémicos por su evidente significación política. Esa cifra sería similar, mutatis mutandis, a los indultos que se aprobarían «como máximo» a lo largo de todo un año, pues como se vino en apuntar desde el Ministerio de Justicia al tiempo que éstos se concedían, tomando como referente la década de los noventa, el número de indultos concedidos oscilaría entre cuatrocientos cincuenta y mil quinientos. En todo caso, lo cierto es que las cifras actuales serían muy inferiores, acentuando más, si cabe, lo sorprendente de aquella medida; así, por ejemplo, en 2004 y 2005 sólo se habrían concedido poco más de trescientos y cuatrocientos indultos, respectivamente. La discusión sobre la aprobación de esta medida no se limitó, en todo caso, al número exageradamente elevado de indultos concedidos, sino igualmente a la motivación esgrimida para su concesión, sobre la que huelga hacer comentarios ahora: el cambio de milenio, la petición de la Santa Sede por ser año jubilar, la celebración del vigesimosegundo aniversario del texto constitucional y los veinticinco años de la Monarquía». 
de los ordenamientos occidentales y que, según autores como Díez Picazo «sigue teniendo sentido en un moderno estado democrático de Derecho» ${ }^{5}$.

En nuestro país, el indulto se encuentra regulado por la Ley de 18 de junio de 1870 de Reglas para el ejercicio de la Gracia de Indulto ${ }^{6}$. Recoge los tipos de indulto (total o parcial) (art. 4), los casos en los que puede concederse $(\text { art. } 1)^{7}$ y en los que no $(\text { art. } 2)^{8}$, el procedimiento para solicitarlo y conceder$10^{9}$, además de una serie de mandatos dirigidos al Gobierno y a los que éste debe atenerse para la concesión de los mismos, como la obligación de mencionar expresamente la pena principal sobre la que recae el indulto (art. 5), la imposibilidad de extender la gracia a la indemnización civil (art. 6) ${ }^{10}$ y a las costas procesales (art. 9), la necesidad de que exista informe del tribunal sentenciador (art. 23), y la obligación de aportar al expediente los informes del Fiscal, de la parte ofendida ${ }^{11}$ y del Jefe del establecimiento donde se esté cumpliendo la condena —en este caso, el informe se referirá a la conducta del penado- (art. 24).

Esta ley fue modificada por la Ley 1/1988 de 14 de enero, en diferentes aspectos, siendo lo más destacable la eliminación de la motivación preceptiva en los indultos parciales: Se mantuvo para los totales pero no para los parciales. Así, el art. 11 de la LI dice: «El indulto total se otorgará a los penados tan solo en el caso de existir a su favor razones de justicia, equidad o utilidad pública, a juicio del Tribunal sentenciador». Para el resto de los casos (es decir, cuando no medien las razones expuestas), se concederá tan solo el indulto parcial (art. 12). A este asunto también nos referiremos más delante, en un apartado específico sobre la motivación, dada su relevancia dentro del comentario.

5 DÍEZ-PICAZO, L. M., en su voto particular a la STS de 20 de noviembre de 2013, dice al respecto: «El derecho de gracia sirve para moderar un posible rigor excesivo, no hay que pensar únicamente en aquellos casos en que razones de equidad o de justicia material aconsejan una reducción o un perdón de la pena impuesta. El derecho de gracia también puede cumplir una importante función en aquellos otros casos en que sin que medien serias razones de equidad o de justicia material a favor del reo, otras consideraciones de interés general aconsejan la clemencia. Piénsese (...) en la necesidad de asegurarse la colaboración de confidentes en organizaciones criminales o la de suavizar conflictos en las relaciones internacionales. (...) el derecho de gracia es un instrumento de la política y que, en cuanto tal, su ejercicio responde a valoraciones especialmente políticas»

6 Las disposiciones sobre la gracia de indulto son anteriores a la Ley de 1870. Esta fue derogada parcialmente en varias ocasiones y restablecida con posterioridad. Vid. HERRERO HERRERO, I., «Antecedentes y evolución histórica de la legislación sobre el indulto», en Revista de Derecho de la UNED, núm. 10, 2012, pp. 687 y ss.

7 Art. 1 LI 1870: «Los reos de toda clase de delitos podrán ser indultados...»

8 Ver también art. 3.

9 Capítulo III LI de 1870. Arts 19 a 32.

10 En este sentido también el art. 15.1. ${ }^{\text {a }}$ LI 1870: «Serán condiciones tácitas de todo indulto: que no causen perjuicio a tercera persona o no lastime sus derechos»

11 En este sentido también el art. 15.2. ${ }^{a}$ LI 1870: «Serán condiciones tácitas de todo indulto: que haya sido oída la parte ofendida, cuando el delito por el que hubiese sido condenado el reo fuera de los que solamente se persiguen a instancia de parte». 
El ejercicio del derecho de gracia no ha suscitado tradicionalmente gran interés, ni social ni informativo, algo que afortunadamente está cambiando ${ }^{12}$, seguramente debido a la concesión de indultos en casos de gran alarma social. Así, por ejemplo, uno de los casos más sonados fue el indulto concedido a varios mossos d'escuadra que habían sido condenados por torturas. En realidad se les concedieron dos indultos - a falta de uno- . En el primero se rebajaba la pena privativa de libertad a dos años para que no ingresaran en prisión, pero a pesar de ello, el tribunal sentenciador decidió su ingreso en la cárcel, lo que dio lugar a la concesión de un segundo indulto sustituyendo la pena de prisión por una de multa ${ }^{13}$. Estos indultos supusieron un gran escándalo no solo social; incluso varios centenares de jueces — de diferentes categorías y asociaciones- se manifestaron en contra ${ }^{14}$, al igual que algunos partidos políticos ${ }^{15}$.

El Tribunal Supremo, consciente de la gran cantidad de abusos que se llevan cometiendo desde hace años con los indultos y conocedor de la gran alarma social que suscitó su concesión en el asunto de los mossos, pidió al Gobierno que razonara la concesión de indultos. Y es en este punto, donde se centra en gran medida, el

12 El indulto que dio lugar a la sentencia que hoy nos ocupa tuvo más repercusión que las anteriores, llegando la polémica hasta el Congreso. No nos cabe duda que la reacción de los medios de comunicación, la judicatura y otros sectores de la población provocó sus efectos en el Gobierno, lo que se pone de manifiesto por la notable disminución de indultos concedidos desde la fecha. En 2009 se concedieron 421. En 2010 fueron 386. En 2011, 301. En 2012, 501. En 2013, el número bajó a 190, para situarse en los 61 durante los 5 primeros meses de 2014. En la actualidad, solo se dedica a los indultos un Consejo de Ministros al mes y los expedientes se envían directamente a la Presidencia de Gobierno, mientras que antes se les dedicaba mucho más tiempo y se remitían al Ministro de Justicia. Vid. AGUADO RENEDO, C., Problemas constitucionales del ejercicio de la potestad de gracia, Madrid, Civitas, 2001. Pág. 224

13 En los RD 1602, 1604, 1606, 1609/2012, de 23 de noviembre (BOE núm. 297, de 11 de diciembre) se recogen los indultos. Se indica que los autores habían sido condenados por un delito de torturas a la pena de tres años de prisión, con la inhabilitación especial para el derecho de sufragio pasivo durante el tiempo de la condena e inhabilitación absoluta por tiempo de nueve años; y un delito de lesiones, a la pena de un año y seis meses de prisión, también por inhabilitación especial, por hechos cometidos en el años 2006. En el primer indulto se conmutó la pena privativa de libertad por otra de dos años de prisión, y la inhabilitación por dos años de suspensión para empleo o cargo público. En el Consejo de Ministros de 23 de noviembre de 2012 se concede un segundo indulto en el que la pena privativa de libertad pendiente de cumplimiento se conmuta por otra de dos años de multa.

14 PERAL, M., en el diario El Mundo de 30-11-2012 (versión digital) bajo el título «Doscientos jueces se rebelan contra el indulto a "mossos" torturadores» dice que jueces firmantes de un escrito señalan que la actuación del Gobierno en este caso supone un menosprecio a los miles de agentes de policía que a diario cumplen sus funciones».

15 En una proposición de Ley presentada por el Grupo Parlamentario de IU, ICV-EUiA, CHA: La Izquierda Plural, para la reforma de la Ley de 1870 del ejercicio de gracia de indulto (BOCG, Congreso de los Diputados, Serie B, núm. 144-1, de 22-11-2013) introduce reformas en los artículos 5, 11, 30, 33,34 y propone añadir un nuevo artículo 35. En el art. 5 pide la incorporación del motivo que justifique la concesión del indulto; otra proposición de Ley de UPyD fue debatida en la Comisión de Justicia celebrada el 17-12-2013 (Diario de Sesiones del Congreso de los Diputados núm. 486, pp. 24 y ss.), también aquí se pedía la motivación de los indultos. No obstante la proposición fue rechazada por 23 votos en contra y 18 a favor. Proposición de Ley de reforma de la Ley del Grupo Parlamentario Socialista (BOCG, Congreso de 
interés constitucional sobre el derecho de gracia: si existe o no la obligación de motivar la concesión de los mismos.

\section{SENTENCIA DEL PLENO DE LA SALA DE LO CONTENCIOSO-ADMINISTRATIVO DEL TRIBUNAL SUPREMO DE 20 DE NOVIEMBRE DE 2013}

La Sentencia que nos ocupa trae causa de un recurso interpuesto contra un indulto concedido por el Real Decreto de 5 de enero de 2013 en el que se conmutaba una pena de 13 años de prisión y la inhabilitación correspondiente, por la de dos años de multa. El sujeto había sido condenado por un delito de conducción con grave desprecio para la vida de los demás en concurso con un delito de homicidio, un delito de lesiones, una falta de lesiones y una falta de daños ${ }^{16}$.

Los recurrentes, entre otras alegaciones, impugnan el Real Decreto por 1) incumplimiento de elementos reglados en la concesión del indulto al incumplirse la finalidad perseguida por la LI con la consiguiente desviación de poder, 2) infracción de los artículos 9.3, 10.1 y 103.1 CE dada la inexistencia de motivación en la concesión del indulto, lo que lo convertiría en arbitrario, 3) por inconstitucionalidad del mismo 4) por infracción del principio de igualdad (art. 14 CE) 5) Por infracción del art. $24 \mathrm{CE}^{17}$.

La Sala de lo Contencioso-Administrativo del TS estimó el recurso seguramente teniendo en cuenta los abusos que desde hace años, como hemos dicho, se vienen produciendo en torno a la concesión de indultos. No obstante, en la primera redacción se desestimaba, pero ante una mayoría adversa el ponente fue sustituido ${ }^{18}$ y finalmente se estimó. Aún así, 19 de los 36 Magistrados emitieron voto particu-

los Diputados, Serie B, núm. 154-1, de 17-01-2014), pide que en el art. 5 se incorpore la motivación por la que se concede el indulto y en el 30: «la concesión de los indultos, cualquiera que sea su clase, se hará en real decreto motivado...».

16 Recoge el RD 1668/2012 de 7 de diciembre (BOE núm. 5, de 5 de enero de 2013): «Visto el expediente de indulto de don R. J. R. S., condenado por la Audiencia Provincial ... en sentencia de 17 diciembre de 2011, como autor de un delito de conducción con grave desprecio para la vida de los demás en concurso ideal con un delito de homicidio, un delito de lesiones, una falta de lesiones y una falta de daños, a la pena de trece años de prisión e inhabilitación ... Vengo en conmutar a don R. J. R. S. la pena privativa de libertad pendiente de cumplimiento por otra de dos años de multa...».

17 En la sentencia se da repuesta a todas estas pretensiones salvo a la última. No se pronuncia sobre la petición de inconstitucionalidad, seguramente porque dicha inconstitucionalidad se hace depender de la supuesta arbitrariedad en la concesión y en la falta de motivación, algo a lo que se refiere la resolución ampliamente al referirse a las pretensiones anteriormente mencionadas.

18 En el párrafo segundo del decimoprimero de los antecedentes de hecho de la sentencia se recoge: «Siendo designado inicialmente Ponente el Excmo. Sr. D. C. Lesmes Serrano, Magistrado de la Sala, y visto el resultado de la votación, el mismo declinó la redacción de la sentencia, que fue asumida por el Excmo. Sr. D. R. Fernández Valverde, igualmente Magistrado de la Sala». 
$\operatorname{lar}^{19}$, dando lugar a una sentencia compleja y reiterativa, difícil de interpretar ${ }^{20} \mathrm{y}$, en ciertos puntos, contradictoria ${ }^{21}$ e incluso incongruente ${ }^{22}$.

Uno de los problemas con los que se encontraron los Magistrados — como ellos mismos reconocen en el texto- al abordar este asunto, fue que no había una jurisprudencia consolidada sobre supuestos de anulación de indultos. La Sala se había pronunciado sobre esta cuestión en 28 ocasiones, pero solo en 4 de ellas se abordaba el tema de la concesión (manifestándose en las demás sobre la denegación). A pesar de ello, alguno de los ponentes consideró que sí podía hablarse de la existencia de una jurisprudencia sobre aspectos generales de los indultos y que, de hecho, esta sentencia suponía un cambio en la misma ${ }^{23}$, en lo referente a la cuestión de la motivación.

Y es precisamente el tema de la motivación, el que pasó a ocupar el lugar central de la controversia. El Gobierno no había especificado en el Decreto de concesión, las razones de justicia, equidad o utilidad pública por las que se otorgaba el indulto, algo que según la sentencia del TS y la opinión de algunos ponentes ${ }^{24}$ era preceptivo, si bien esa obligación desapareció de la Ley con la reforma del 1988 (lo que ponen de manifiesto otros ponentes) ${ }^{25}$.

19 De los 36 magistrados del pleno que firman la sentencia 19 de ellos emitieron voto particular. Se agrupan en siete votos particulares: tres fueron a título particular, tres firmados por dos magistrados y uno por 10. En dos se pide la inadmisión del recurso (uno a título particular y el otro el de diez magistrados interpuesto por el primer ponente, al que se adhieren otros nueve). En todos ellos hay discrepancias y observaciones a la sentencia.

$20 \mathrm{Vid}$. CÓRDOBA RODA, «El indulto y el control judicial de su concesión», en Revista Jurídica de Catalunya, núm. 1, 2014, pp. 68 y ss., dice que se trata de una resolución «importante y compleja sentencia», "parece haber modificado esta doctrina», «de forma algo confusa», «de manera más imprecisa», «interpretación muy forzada», «de modo algo contradictorio», «ciertamente confuso», «razonamiento que nos plantea algunas dudas».

21 Carlos Lesmes Serrano en su voto particular a la STS de 20 de noviembre de 2013, al que se adhirieron otros diez magistrados (R. Enríquez Sancho, P. J. Yagüe Gil, M. Campos Sánchez-Bordona, J. Díaz Delgado, W. Francisco Olea Godoy, A. J. Fonseca Herrero Raimundo, D. Córdoba Castroverde, V. Conde Martín de Hijas y M. Martín Timón) recoge una serie de contradicciones en las que, a su modo de ver, incurre la sentencia del TS. La primera contradicción viene determinada porque la sentencia «iguala desde la perspectiva de control de los elementos reglados, el acto administrativo discrecional y el acto de ejercicio de la prerrogativa de gracia», para a continuación reconocer que la desviación de poder es una técnica de control del acto discrecional pero no lo es del indulto. La segunda contradicción tiene que ver con la motivación, pues la STS, a pesar de reconocer que ésta queda fuera de la ley tras la reforma de 1988, termina por estimar el recurso precisamente por la falta razones de justicia, equidad o utilidad pública.

22 J. E. Peces Morate, en su voto particular a la STS de 20 de noviembre de 2013, al que se adhirió M. de Oro-Pulido y López, dice: «Incurre, a mi parecer, la sentencia de la Sala en una incongruencia interna porque abunda en consideraciones acerca de la innecesariedad de motivar el ejercicio de gracia (...) mientras que en el primer pronunciamiento de la parte dispositiva de dicha sentencia anula el real Decreto de concesión del indulto impugnado»

23 L. M. Díez-Picazo, en su voto particular a la sentencia de 20 de noviembre de 2013, dice al respecto: «Esta sentencia supone, por todo ello, una innegable modificación jurisprudencial, algo que, siempre que se haga de manera razonada, es perfectamente legítimo.»

24 Ver, por ejemplo, el voto particular de Eduardo Espín Templado, al que se adhirió C. Pico Lorenzo.

25 Véase, por ejemplo, el voto particular de Jorge Rodríguez Zapata. 


\section{Aproximación al indulto}

Frente a las pretensiones expuestas por los recurrentes, el tribunal parte de la configuración constitucional del indulto para más adelante pasar a responder cada una de dichas pretensiones (salvo la referente a la inconstitucionalidad).

Así, tras recordar que solo caben los indultos particulares pero no los generales ni la amnistía, asevera que constituye el ejercicio del derecho de gracia, que se trata de una medida individual y excepcional ${ }^{26}$ del Gobierno que, según el TS, no puede encuadrarse en la antigua categoría de actos políticos ni considerarse acto administrativo ${ }^{27}$. No obstante, «tiene como núcleo esencial y ratio essendi, su carácter discrecional» (FJ 6), lo que significa que se trata de un acto no debido ${ }^{28}$. Aunque se solicite la gracia, el Gobierno no está obligado a concederla ${ }^{29}$.

Así pues, como medida excepcional ${ }^{30}$ que es, solo está llamada a proveer medidas igualmente excepcionales y, en todo caso, está «sujeta a la ley» correspondiéndole al poder judicial «velar por la efectividad de esa ejecución, precisamente porque comporta cierta derogación del principio de generalidad de la ley penal y de los de independencia y exclusividad de la jurisdicción» (FJ 6, 2. ${ }^{\circ}$ ).

Los elementos que deben concurrir para que el indulto se pueda conceder y que se enumeran en la LI son:

a) Que concurran - y se hagan constar en el informe que emita el Tribunal sentenciador - razones de justicia, equidad o utilidad pública para la concesión de indultos totales. En consecuencia, a falta de dichas razones o del informe, el indulto

26 En este sentido, STS de 20 de febrero de 2013: «es una potestad extraordinaria de intervención de un poder estatal, el ejecutivo, en el ámbito de competencia de otro, el judicial, de manera que... su uso debe estar rodeado de cautelas y límites, con el objeto de procurar la menor perturbación posible para el orden jurídico».

27 «Ni el ejercicio del derecho de gracia es una actuación administrativa, ni, en consecuencia, su materialización mediante el indulto supone el ejercicio de potestades administrativas, en los términos que hemos expuesto; por ello, la técnica de control del derecho de gracia a través de la desviación de poder no puede ser invocada — como pretenden los recurrentes» $\left(\mathrm{FJ} 6,5^{\circ} .^{\circ}\right.$. «Se deduce que el legislador admite la existencia de actos de gobierno de naturaleza no administrativa exentos de control ordinario de legalidad y solo controlables en sus elementos reglados, cuando resulten afectados derechos fundamentales o para hacer efectiva la garantía patrimonial».

28 «Dogmáticamente dicha diferencia bien pudiera mantenerse, lo cierto es que, una vez cumplidos todos los requisitos procedimentales previstos en la $\mathrm{Ll}$ (Ley de indulto) para la concesión de un indulto, el órgano competente para ello —el Gobierno, que no el Rey - reunido en Consejo de Ministros, puede conceder, o no, la gracia solicitada, de modo que no se encuentra obligado a hacerlo» (FJ 6, 3..$^{\circ}$.

29 La sentencia insiste, además, en que se trata de un acto con rasgos de atipicidad en el marco del Estado constitucional de Derecho. (FJ 7).

30 STS de 20 de noviembre de 2013, FJ 6: «Es una potestad extraordinaria de intervención de un poder estatal, el Ejecutivo, en el ámbito de competencia de otro, el Judicial, de manera que, una vez constitucionalmente admitida la prerrogativa por la razón indicada, su uso ha de estar rodeado de cautelas y límites, con objeto de procurar la menor perturbación posible para el orden jurídico, marcando así una diferencia sustancial entre la prerrogativa de gracia aceptada en el Estado constitucional con la indulgencia principis propia de la Roma Imperial o de las Monarquías absolutas, cuyo ejercicio y extensión no respondía a más voluntad que la de su titular». 
solo podrá ser parcial. b) En el caso de indulto parcial, la pena impuesta se conmutará por otra menos grave dentro de la misma escala ${ }^{31}$ o por otra de diferente escala si se cumplen las siguientes condiciones: que existan méritos suficientes para ello, que así se diga en el informe del Tribunal sentenciador y que el penado se conforme con la conmutación.

\section{2. ¿Hasta dónde llega el control en la concesión de indultos?}

Respecto al posible control sobre la concesión de indultos por parte del Gobierno, el TS se ha pronunciado de forma clara, y es reiterada jurisprudencia de la Sala de lo contencioso del Tribunal Supremo que dicho control «lo es exclusivamente en lo que a los aspectos formales de tramitación se refiere, pues en sus aspectos sustantivos - la decisión del Gobierno - no es susceptible de sustitución por la valoración del propio interesado o de los órganos jurisdiccionales» (FJ 5 e).

La controversia no surge en torno a si los actos de concesión de los indultos pueden estar o no fiscalizados por el Poder Judicial ${ }^{32}$, pues no parece haber duda en que sí pueden estarlo. Lo que no queda tan claro es hasta dónde puede llegar ese control cuando nos encontramos ante actos de máxima discrecionalidad, como son los indultos ${ }^{33}$.

Debemos entender que todos los actos llevados a cabo por el Gobierno, por discrecionales que sean, deben estar sometidos a la Constitución, a la ley y al Derecho $^{34}$ y son «los Tribunales de lo contencioso Administrativo los que han de asumir aquel control, incluso frente a actos gubernamentales de dirección política, cuando el legislador haya definido mediante conceptos judicialmente asequibles los límites o requisitos previos a los que deben sujetarse para comprobar si el Gobierno ha respetado aquellos y cumplidos estos al tomar la decisión de que se trate» ${ }^{35}$.

No obstante, ese control sólo podrá concretarse en los aspectos formales del indulto — esto es, en si concurren o no los elementos reglados—, no pudiendo

31 La referencia apenas de la misma escala debe obviarse, dado que aunque estas existían en el Código penal de 1850, vigente cuando se redactó la LI de 1870, no perduran hoy en día. Ya que el vigente Código Penal no contempla escalas graduales de las penas en el sentido recogido en la LI.

32 STS de 20 de noviembre de 2013 (FJ 8): «En el supuesto concreto del indulto (STS 20 de febrero de 2013) nos acercamos a dichas consideraciones al señalar que «El indulto no es indiferente a la Ley, muy al contrario es un quid alliud respecto de la Ley, y, por tanto, no puede ser ajeno a la fiscalización de los Tribunales, pues en un Estado constitucional como el nuestro, que se proclama de Derecho, no se puede admitir un poder público que en el ejercicio de sus potestades esté dispensado y sustraído a cualesquiera restricciones que pudieran derivar de la interpretación de la Ley por los Tribunales».

33 Ver en este sentido las SSTS de 17 de diciembre de 1992, de 29 de abril de 1993 y de 6 de febrero de 1995, entre otras. STS de 4 de abril de 1997: «la importante tradición de la jurisdicción contencioso administrativa dirigida a reducir las inmunidades del poder público»

34 STS de 2 de diciembre de 2005. Ver art. 2 LRJCA: «el orden jurisdiccional contencioso administrativo conocerá de las cuestiones que se susciten en relación con a) la protección de los derechos fundamentales, los elementos reglados y la determinación de las indemnizaciones que fueran procedentes, todo ello en relación con los actos del Gobierno... cualquiera que fuera la naturaleza de dichos actos»

35 STS de 4 de abril de 1997. 
extenderse a la valoración de los requisitos de carácter sustantivo ni a la falta de motivación, ya que como vimos al enumerar los elementos reglados, aquella no era uno de estos ${ }^{36}$, puesto que fue eliminada de la Ley en relación a los indultos parciales en la reforma de 1988.

La sentencia no deja lugar a dudas sobre este extremo. En su FJ 6-5), expone claramente que los indultos no son actos administrativos ${ }^{37}$ y que, por tanto «no resultan de aplicación al caso los requisitos que para los auténticos actos administrativos establece la Ley 30/1992, y entre ellos, y fundamentalmente, el de la motivación, que no es exigible en las decisiones que sobre el ejercicio del derecho de gracia se adopten por el Gobierno» ${ }^{38}$.

Así pues, solamente se pueden controlar los actos reglados que se contemplan en la Ley de 1870 (modificada en 1988) y a los que ya nos referimos en el apartado anterior. ${ }^{39}$ La doctrina se ha pronunciado en el sentido de que el ejercicio del derecho de gracia puede ser objeto de control parlamentario ${ }^{40}$.

\section{Motivación y razones de justicia, equidad y utilidad social}

Hasta 1988, la motivación era un requisito esencial que limitaba la concesión de indultos a aquellos que estuvieran efectivamente motivados. Este requisito legal respondía al espíritu de la ley, descrito en su exposición de motivos, donde se decía que «el indulto no debe concederse sino con pleno conocimiento de los hechos y de todas sus circunstancias, y después de un estudio detenido sobre las consecuencias que hay de producir, bajo el aspecto de la justicia, la equidad o de la conveniencia social. (...) Mas, si debe ser ilimitada la libertad de pedir, es necesario poner fuertes trabas a la de conceder el indulto. (...)», pero la LI fue modificada y desapareció la

36 Así, en la STS de 29 de mayo de 2013 (RC 441/2012) hemos señalado que esta Sala «con reiteración viene expresando, a la hora de delimitar el alcance del control jurisdiccional contencioso administrativo de los acuerdos de indulto, que se encuentra limitado a los aspectos formales de su elaboración, esto es, a los aspectos reglados del procedimiento, concretamente, a si se han solicitado los informes preceptivos y no vinculantes que la Ley 1/1998 establece, sin extenderse a defectos de motivación ni, por supuesto, a la valoración de los requisitos de carácter sustantivo».

37 STS de 11 de diciembre de 2012: «El indulto, estrictu sensu, no es un acto administrativo (...) el derecho de gracia constituye una facultad potestativa no susceptible de ser combatida ante la Jurisdicción contencioso-administrativa, salvo cuando se incumplan los trámites adoptados para su adopción».

38 STS de 23 de enero de 2013.

39 Los artículos 2, 9, 11, 23 y 24 se modifican por la Ley 1/1988, de 14 de enero, por la que se modifica la Ley de 18 de junio de 1870 , estableciendo reglas para el ejercicio de la gracia de indulto (BOE núm. 13 , del 15).

40 LINDE PANIAGUA, E., «El indulto como acto de administración de justicia y su judicialización. Problemas, límites y consecuencias», en Teoría y Realidad Constitucional, núm 5, 2000, en pp. 170 y s. se ocupa del control parlamentario de la potestad de conceder indultos. LÓPEZ AGUILAR, J. F., por su parte, en «Una reflexión a propósito del control parlamentario del ejercicio del derecho de gracia», en Revista de las Cortes Generales, núm. 37, 1996, p. 341, escribe: «Las Cortes Generales pueden controlar la actuación política del Gobierno en la Administración de la prerrogativa de gracia (arts. 66, 97, 108 a 114). Prerrogativa que ejerce, no se descuide, el Rey, con el correspondiente refrendo del miembro del Gobierno correspondiente». 
obligatoriedad de motivar los indultos parciales, quedando dicha obligación vinculada, tan solo, a los indultos totales ${ }^{41}$.

El asunto de la motivación es el tema que centra el mayor desacuerdo entre los magistrados y las mayores contradicciones dentro de la sentencia. De un lado se posicionan los que defienden que la motivación debe ser exigida a pesar de que haya desaparecido de la ley, del otro aquellos que asumen que si desapareció de la ley como elemento reglado no puede ser tomada en consideración ahora, veintiséis años después, como causa de desestimación del recurso, por mucho que se desprenda del espíritu de la ley, esté reflejado en su exposición de motivos (redactada en 1870, hace casi un siglo y medio). Este es el asunto sobre el que la sentencia muestra mayores contradicciones, porque a pesar de asumir que la motivación desaparece como elemento reglado por no ser exigido ya por la ley, y a pesar de considerar que tampoco le es aplicable al indulto la motivación que se contempla en el art. 54.1 de la LRJPA ${ }^{42}$, al final da la vuelta a la argumentación, para terminar estableciendo que los indultos, aunque sean parciales, deben responder a motivos de justicia, equidad o utilidad social, motivos que deben ser explicados ${ }^{43}$. La sentencia recurre a la exposición de motivos de 1870 para intentar defender la motivación de los indultos, como hemos dicho antes, obviando el hecho de que la exposición de motivos de una ley no puede anteponerse a la letra de la misma. Así, en este sentido, dice la STS de 20 de noviembre de 2013: «Como no es un acto administrativo, no puede exigirse al Acuerdo de concesión o denegación del mismo una motivación en el sentido técnico que requiere la LRJPA, pero no es menos cierto que por la misma ley de indulto se exige que del acuerdo de indulto se desprendan las razones de justicia, equidad o utilidad pública a las que, de forma expresa se refiere en su art. 11; razones a las que también alude su exposición de motivos cuando señala que al concesión del indulto ha de llevarse a cabo con pleno conocimiento de los hechos y de todas sus circunstancias, y después de un estudio detenido sobre las consecuencias que haya de producir, bajo el aspecto de la justicia, la equidad o la conveniencia social». (JF 8).

El Tribunal, tras admitir que no podía intervenir en la decisión de indultar o no, ni revisar las razones contenidas en la documentación aportada a los expedientes

41 La Ley de 1870 fue modificada en 1988, el artículo 30 inicial que antes decía «la concesión de indultos, cualquiera que sea su clase se hará en decreto motivado y acordado en Consejo de Ministros», tras la reforma desaparece la referencia a la motivación. Ahora reza: «La concesión de indultos, cualquiera que sea su clase, se hará en Real Decreto».

42 Según el art. 54.1 de la Ley de Régimen Jurídico de las Administraciones Públicas y del Procedimiento Administrativo Común (Ley 30/1992) (LRJPA): «Serán motivados, con sucinta referencia de hechos y fundamentos de derecho: a) los actos que limiten derechos subjetivos o intereses legítimos». Según la STS de 20 de noviembre de 2013, «No resultan de aplicación al caso los requisitos que para los auténticos actos administrativos establece la Ley 30/1992, y entre ellos, y fundamentalmente, el de la motivación, que no es exigible en las decisiones que sobre el ejercicio del derecho de gracia se adopten por el Gobierno».

43 STS de 20 de noviembre de 2013: «El control jurisdiccional no puede extenderse a los efectos de motivación del indulto..., pero no es menos cierto que por la misma Ley de indulto se exige que del acuerdo de indulto se desprendan las razones de justicia, equidad o utilidad pública». 
(tan solo comprobar que el requisito formal se cumplía) y después de admitir que la motivación no se encuentra entre los elementos reglados y que por tanto ni es preceptivo que figure ni puede ser exigido judicialmente, dio la vuelta a toda su argumentación ${ }^{44}$ — como ya se ha venido apuntando- para terminar diciendo que sí se puede exigir al Gobierno que incluya en el acuerdo de indulto la explicación sobre qué circunstancias de justicia, equidad o utilidad social le han llevado a conceder la gracia. Dice la sentencia en este sentido: «Si el legislador ha establecido la obligación de seguir un procedimiento para la concesión o denegación de los indultos, que ha de materializarse y documentarse en un expediente administrativo, y si el mismo legislador exige que consten siempre razones que le motiven a ejercer la prerrogativa constitucional, obvio es que el legislador ha pretendido que de esa tramitación documentada se desprendan las tan citadas razones de justicia, equidad o utilidad pública, legalmente exigibles, pues, de otra forma, la absoluta inutilidad del expediente de indulto resultaría clamorosa» (FJ 8).

Parece que el Tribunal busca la forma de exigir cierta base a los indultos parciales aun a sabiendas de que no puede exigir motivación alguna. Así que finalmente lo llama «control meramente externo» cuando en realidad se trata de exigir «un proceso lógico que no puede resultar arbitrario, y del que ha de desprenderse que las expresadas razones no son una construcción en vacío». Es decir, se exige explicar por qué se concede el indulto — poniendo como pretexto la ley_, que no es otra cosa que poner en boca de la ley lo que no dice. Lo dijo, eso sí, pero ya no lo dice, lo que indica, además, que no hace referencia a la motivación para los indultos parciales porque no quiere hacerlo. El legislador decidió modificar la ley precisamente para eliminar ese elemento. Así pues, nos parece un error pretender creer que la ley, aunque eliminó la exigencia de motivación para estos casos, lo hizo queriendo que se mantuviera.

Otro de los argumentos que se esgrimió en defensa de la obligatoriedad de la motivación del Acuerdo de indulto fue la referencia a interdicción de la arbitrariedad de los poderes públicos.

\section{Interdicción de la arbitrariedad de los poderes públicos}

Este elemento fue introducido por los recurrentes quienes parecían querer agotar todas las posibilidades al entender que el indulto tiene carácter discrecional y que la motivación ya no era preceptiva desde 1988. Así, plantearon la cuestión de si, en los términos establecidos por los actos administrativos, se podría «con-

44 «Pero sí debemos enjuiciar si las razones de justicia, equidad y utilidad pública — que necesariamente deben de constar en el Acuerdo y que puedan responder a muy distintas causas (que pueden ir desde las de carácter penitenciario social a las de carácter personal o familiar) — cuentan con el apoyo real reconocible en los elementos reglados o formales que componen el expediente »Dicho de otra forma, entre la decisión de indultar (en modo alguno revisable jurisdiccionalmente) y la especificación de las «razones de justicia, equidad o utilidad pública» (legalmente exigibles), se nos presenta un espacio jurisdiccionalmente «asequible», por el que debe transitarse con los instrumentos de la lógica jurídica» (FJ 8). 
trolar el ejercicio del derecho de gracia desde la perspectiva de la interdicción de la arbitrariedad de los Poderes Públicos». El Tribunal contestó afirmativamente a dicha pretensión, abriéndose un nuevo camino en la dirección tomada desde el principio por el Pleno, en el sentido de exigir una justificación del indulto. Dice el Tribunal: «En fin, que la lógica jurídica en dicho proceso de decisión administrativa se nos presenta como el parámetro exterior de contención de la arbitrariedad, proscrita para todos los Poderes Públicos en el artículo 9.3 de la CE, ya que, al fin y al cabo, la actuación arbitraria es la contraria a la justicia, a la razón o a las leyes, y que obedece a la exclusiva voluntad del agente público. Lo que en dicho precepto constitucional se prohíbe es la falta de sustento o fundamento jurídico objetivo de una conducta administrativa, y, por consiguiente, la infracción del orden material de los principios y valores propios del Estado de Derecho. Y tal exigencia también ha de reclamarse cuando del derecho de gracia se trata, aunque en el marco de la mayor discrecionalidad de que la misma está investida». (FJ 8)

Este principio supone el control, por parte de los tribunales, de los abusos de los poderes públicos. Con él se «aspira a evitar que se traspasen los límites nacionales de la discrecionalidad y se convierta esta en causa de decisiones desprovistas de justificación fáctica alguna... Para no incurrir en arbitrariedad la decisión discrecional debe venir respaldada y justificada por los datos objetivos sobre los cuales opera ya que los actos discrecionales al existir en mayor o menor medida libertad estimativa resulta de gran trascendencia el proceso lógico que conduce a la decisión». (FJ 8)

De este modo, el Tribunal introdujo otro factor a favor de la obligatoriedad de incluir cierta motivación en los acuerdos de concesión del indulto.

Esta argumentación tuvo mejor acogida entre los magistrados, pero aun así, la mayoría de los que se manifestaron a través de sus votos particulares lo hicieron para oponerse a tal posibilidad. Eduardo Espín Templado, favorable a esta fórmula dice: «No puede afirmarse, desde luego, que la Constitución requiera en concreto que los Decretos de indulto estén motivados. Pero sí ha de entenderse que tales actos de poder público, aunque constituyan un acto graciable — no exigido por derecho alguno del indultado- están vinculados por la proscripción de la arbitrariedad establecida por el artículo 9.3 de la Constitución — precisamente la razón que ha llevado al Pleno a estimar el recurso-. Pues bien, qué duda cabe de que la mejor manera de excluir la arbitrariedad es expresar de manera explícita las razones que han llevado al Consejo de Ministros a otorgar el indulto a una determinada persona mediante la debida motivación.» ${ }^{45}$.

45 Otros magistrados que se manifestaron en esta línea José Juan Suay Rincón: «Centrado ahora nuestro examen en el principio constitucional de interdicción de la arbitrariedad de los poderes públicos, no me parece, en primer término, que resulte especialmente relevante su consideración técnica como uno de los elementos reglados normativamente prefigurados (lo está en la propia norma constitucional, sin la menor duda). De considerarse así, autorizaría ello pacíficamente su control en sede jurisdiccional.

Pero, de no considerarse así, es el caso que constituye también de cualquier modo un principio general del Derecho, que igualmente legitima el ejercicio de la fiscalización jurisdiccional: dicho principio no sólo puede esgrimirse en presencia de potestades discrecionales en sentido estricto (consideradas éstas solo las en- 
En contra se expresa el magistrado Luis María Díez-Picazo, al entender que a pesar de ser muy deseable el control sobre los indultos, este solo puede ser sobre los elementos reglados. Así, rechaza la posibilidad de encauzar la exigencia de motivación por vía del art. $9 \mathrm{CE}$, si bien deja claro que los indultos deben ser controlados por la opinión pública. Quizá no se pueda ejercer control jurídico, pero sí un control social. Dice: «Los recurrentes alegan, junto a la falta de motivación, la arbitrariedad del acto impugnado. Esta alegación no puede ser acogida, siendo importante distinguir entre deber de motivación e interdicción de la arbitrariedad. Que la interdicción de la arbitrariedad, proclamada en el art. $9 \mathrm{CE}$, rige para todos los poderes públicos es algo que no puede ser seriamente puesto en duda; y, por tanto, también los «actos políticos» están sometidos a dicho principio. Ahora bien, estos actos —entre los cuales, como quedó dicho más arriba, se hallan el otorgamiento y la denegación del indulto- se caracterizan por ser susceptibles de control jurisdiccional únicamente en lo atinente a «los elementos reglados», tal como dispone el art. 2 LJCA. Ello significa que el remedio frente la eventual arbitrariedad de un acto de esta índole no puede ser buscado en los Tribunales. Es más: la idea misma de arbitrariedad — es decir, de decisión mediante pura voluntad y sin sujeción a regla alguna- sería difícilmente aplicable, en términos de razonamiento jurídico, a los actos graciables; y ello porque graciable es precisamente lo que puede darse o negarse de manera libérrima» ${ }^{46}$. Esta misma postura fue la mantenida por Carlos Lesmes Serrano y los diez magistrados que firmaron su voto particular ${ }^{47}$.

\section{El fallo}

Al final, como se preveía y en contra de la opinión de algunos magistrados —opinión que manifestaron de forma expresa en sus votos particulares ${ }^{48}$ — , el Tri-

caminadas derechamente a la satisfacción de un interés público cuya concreción queda remitida al momento propiamente aplicativo de la norma); y extiende su virtualidad, por tanto, también más allá de ellas hasta comprender la actuación de cualesquiera poderes públicos.»

Jesús Ernesto Peces Morate: «comparto la tesis de los demandantes acerca de la inconstitucionalidad del Real Decreto de concesión del indulto sin motivación, pues ello impide o, al menos, dificulta el control jurisdiccional acerca de la interdicción de la arbitrariedad.»

46 Continúa diciendo en su voto particular: «el control social — que no jurídico- del derecho de gracia por parte de la opinión pública es especialmente necesario, para evitar un ejercicio excesivo o abusivo de aquél».

47 «El respeto y la salvaguarda del principio de división de poderes supone aceptar una serie de limitaciones al acto judicial de control consistentes en atender a la función constitucional que a cada poder le incumbe. La previsión constitucional de la interdicción de la arbitrariedad de los poderes públicos (art. 9.3 CE) (...)» no excluye que existan actos de los órganos constitucionales que tengan asimismo un máximo contenido político, los cuales no son controlables respecto del fondo de la decisión en sede jurisdiccional, sino ante la instancia política correspondiente.

48 En el voto particular emitido por Carlos Lesmes Serrano, al que se adhieren otros 10 magistrados, se disiente del fallo. Consideran que la sentencia «no debería haber anulado el indulto salvo que se considerase que las explicaciones aportadas en el expediente y en sede parlamentaria por el órgano político impulsor del indulto eran ilógicas o arbitrarias». Ya se indicó que la sentencia solo tuvo en cuenta los informes del Ministerio Fiscal y tribunal sentenciador que se oponían a la concesión del indulto. Sin embargo, se omitió la 
bunal estimó el recurso ${ }^{49}$. Además, aplazó la ejecución del fallo de la sentencia tres meses, con el fin de dar al Gobierno la posibilidad de subsanar los errores que a juicio del Tribunal se cometieron en el decreto de indulto ${ }^{50}$ - lo que viene a confirmar de nuevo la insistencia de la Sala en el tema de la motivación de los indultos- ${ }^{51}$. Este aplazamiento ha sido criticado por algunos magistrados en sus votos particulares $^{52}$ y aplaudido por otros. La opinión más discrepante es la de Rodríguez-Zapata, quien entiende que «la sala carece de jurisdicción (...) para posponer en forma expresa la ejecución de un fallo de simple anulación (...) No existe precepto legal en la Ley reguladora de este orden de jurisdicción contencioso-administrativo que lo permita.(...) La institución de deferir la ejecución de una sentencia penal a la espera de un indulto — que se conoce en el Derecho anglosajón como «reprevié»- es una interferencia en el ámbito de la justicia penal que no está atribuida en nuestro Derecho a los Tribunales de lo contencioso-adminsitrativo». Díez-Picazo, por su parte, alude al hecho de cambio jurisprudencial para justificar esta dilación. Entiende que cuando se concedió el indulto, este se ajustaba exactamente a lo exigido en la Ley del Indulto, por lo que si ahora se le exige motivación (lo que no se exige en la Ley), parece lógico que se conceda un plazo de subsanación de errores para poder adaptar la concesión del indulto a las nuevas exigencias ${ }^{53}$.

referencia al informe favorable del centro penitenciario donde cumplía condena el indultado y en el que «se incluían detalladas razones de carácter penitenciario, integración y buena conducta personal y social que apoyaban, a juicio de la Junta de Tratamiento y del Educador del Centro, la concesión del indulto». Aunque si se concediera indulto a todo el que observa buena conducta penitenciaria habría que indultar a la mayoría de los internos de las prisiones españolas. En todo caso en el Reglamento penitenciario está prevista la petición de indulto particular a propuesta del Equipo Técnico, que la solicitará al Juez de vigilancia penitenciaria.

49 Fallo de la STS de 20 de noviembre de 2013. 1. ${ }^{\circ}$ — «Debemos estimar y estimamos el recurso contencioso-administrativo interpuesto... contra el Real Decreto $1668 / 2012 \ldots$ por el que se indulta a D. R. J. R. S.; Real Decreto que anulamos en los términos expresados en el último párrafo del Fundamento Jurídico Séptimo de la presente Sentencia»

50 STS de 20 de noviembre de 2013, F J 9, in fine: «Irremisiblemente ello nos lleva a la anulación del Real Decreto impugnado, con devolución del mismo al órgano de procedencia, para que, en su caso y si a bien lo tiene, su decisión de indultar — que no podemos revisar — sea adoptada en los términos expresados en el texto de la presente sentencia».

51 CÓRDOBA RODA, en ob. cit., p. 75 escribe: «De la interpretación conjunta de algunos de los razonamientos contenidos en la sentencia y de lo dispuesto en el fallo llegamos a la conclusión de que la sentencia se limita a exigir que el Gobierno haga explícitas las razones en base a la cuales concedió el indulto».

52 También se muestran en desacuerdo Carlos Lesmes Serrano en su voto particular — por ende los 10 Magistrados que se adhirieron a este-, José Juan Suay Rincón y M. ${ }^{a}$ Isabel Perelló Domenech (adherida al voto particular de aquel y Jesús Ernesto Peces Morate - junto a Mariano Oro-Pulido y Lopez_, en cuyo voto particular dice: «Si el Pleno de la Sala ha entendido que el Real Decreto de concesión del indulto debe ser anulado por carecer de motivación y justificación, es mi parecer que debió limitarse a emitir un pronunciamiento anulatorio del Real Decreto de indulto, mientras que corresponderá a la Jurisdicción Penal decidir si el beneficiario por el indulto anulado debe o no ingresar de nuevo en prisión y al Consejo de Ministros decidir si le concede un nuevo indulto motivando su decisión».

53 Voto particular de Luis María Díez Picazo: «Cualquiera que sea la valoración que a cada uno merezca el indulto aquí examinado, es lo cierto que, en el momento que fue concedido se ajustaba plenamente a lo exigido por la Ley de Indulto y a la asentada jurisprudencia de esta Sala sobre elementos reglados del derecho de gracia. (...) De aquí que, también desde este otro punto de vista, esté justificado diferir la eficacia del fallo estimatorio y dar un plazo al Gobierno para que acuerde un nuevo indulto con la pertinente motivación». 


\section{CONCLUSIÓN}

El indulto del que trae causa esta sentencia — popularmente llamado caso del kamikaze - tuvo una gran repercusión social, dado que el delito por el que fue condenado el sujeto creó gran alarma social y más aún el hecho de que se le concediera el indulto.

Esta sentencia supone un cambio en la jurisprudencia de la Sala, que hasta este pronunciamiento no había considerado como preceptivo que los indultos parciales fueran motivados, cosa que hace en esta sentencia - aunque se revista con la fórmula de dar una explicación mediante razones de justicia, equidad o utilidad pública $-{ }^{54}$. Hay que partir de la base de que el indulto es una decisión graciable que queda al margen del control judicial — salvo en lo que se refiere a los requisitos formales, obviamente-. Un control que si llegara a ser excesivo podría llegar a desvirtuar la naturaleza del indulto. Esto no quiere decir que nos parezca adecuada la eliminación que en la reforma de 1988 se hizo de la ley —en el sentido de eliminar la obligatoriedad de motivar todos los indultos-, sino todo lo contrario.

Creemos que la ley nunca debió eliminar de su articulado esta obligación, pues lo menos que puede exigirse a un Gobierno que pretende conmutar una pena impuesta por un tribunal legítimo y competente para ello, es que de las razones que le llevan a tomar tal decisión. En el voto particular emitido conjuntamente por diez Magistrados, que se oponen a la estimación del recurso, decían estos: «¿Podemos los Jueces ejercer un control sobre la razonabilidad de una decisión política basándonos en criterios extrajurídicos?». Bueno, pues si la ley recoge esa posibilidad, sí - siempre y cuando no se desvirtúe o vacíe de contenido el derecho de gracia. Esto es, sí, pero siempre que los jueces no pueden influir ni decidir sobre la concesión o denegación de indultos. El problema es que, hoy por hoy, la ley que regula el indulto no contempla tal posibilidad. Es más, la contempló, pero decidió eliminarla de su articulado. Lo que nos lleva a determinar que la ley debe ser objeto de una nueva - y profunda- reforma ${ }^{55}$.

Así pues, coincidimos con la opinión manifestada por el magistrado Jorge Rodríguez-Zapata en su voto particular cuando dice que «entiendo, con todo el respeto, que la Sala se aparta de la debida aplicación del sistema de fuentes del Derecho y se excede en su jurisdicción, al anular una medida de gracias por una exigencia no

54 FERNÁNDEZ ENTRALGO, J., «Indultos y gallinas», en El Mundo de 13 de febrero de 2013, p. 21, considera que establecer la obligatoriedad de motivar los indultos, como se hace en la sentencia que nos ocupa - está «en abierta contradicción con el principio de proscripción de la arbitrariedad en la actuación de los Poderes Públicos, proclamado en el art. 9.3 de nuestra Constitución», dado que según la ley, el Gobierno puede conceder indultos sin motivarlos»

55 Vid. DOVAL PAIS, A. y VIANA BALLESTER, C., «El indulto a revisión. Razones y propuestas para una modificación legislativa», en El Cronista, núm. 107, 2014, pp. 40 y ss. PÉREZ FRANCESCH y DOMÍNGUEZ GARCÍA, en op. cit., pp. 66 y ss. Proponen una amplia reforma de la ley de 1870. Ya en 1981 se aprobó un «Anteproyecto de Ley reguladora de la gracia de indulto», que no llegaría a ser proyecto. Su principal impulsor fue Linde Paniagua, entonces Secretario General Técnico del Ministerio de Justicia. 
prevista ni en la ley que habilita en forma positiva para el ejercicio del derecho de gracia ni en la jurisprudencia unánime de esta sala».

Consideramos, que si efectivamente la Sala consideró que la aplicación de la norma podía dar lugar a un fallo contrario a los valores constitucionales, debió plantearse cuestión de inconstitucionalidad sobre el artículo 30 de la LI de 1988, para resolver el asunto. Esta misma postura fue defendida por el Magistrado Jesús Ernesto Peces Morate, quien cree que el Real Decreto de concesión del indulto podía incurrir en causa de inconstitucionalidad por no estar motivado, "pues ello impide o, al menos, dificulta el control jurisdiccional acerca de la interdicción de la arbitrariedad ${ }^{56}$.

En todo caso la sentencia ha servido para que la opinión pública, los medios de comunicación y la doctrina vuelvan sus ojos hacia esta figura y se medite sobre la reforma de la LI de 1988, que sentó las bases que facilitan la concesión de indultos arbitrarios.

$* * *$

Title: Can we ask Motivation in the Agreement to grant Reprieve? Commentary on the Judgment of the Supreme Court about motivation on reprieves (Judgment of 20 november 2013).

SUMMARY: The judgment in question is a statement of great interest because it comes to changing the line of cases that held granting reprieve. The thing is that a Government's partial reprieve was cancelled because it wasn't not motivated. It is a very controversial decision. In fact, 19 of the 36 judges filed dissenting opinion, most of them referring to the issue of motivation. The controversy arises because the Act of Reprieve does not consider motivation as a mandatory element in the partial reprieves. It was mandatory until 1988, when it disappeared after the law reform. However, the Supreme Court based on the «spirit of the law»-reflected in the preamble and in Article 9.3 $C E$ canceled the reprieve for not giving reasons of justice, equity or social utility for been granted.

Resumen: La Sentencia que nos ocupa es de gran interés porque viene a cambiar la línea jurisprudencial que mantenía hasta abora respecto a la concesión de indultos. Anula un indulto parcial concedido por el Gobierno en base a que éste no lo motivó. Es una resolución muy polémica. De hecho, 19 de los 36 magistrados presentaron voto particular, casi todos ellos en referencia al tema de la motivación. La controversia surge porque la Ley del Indulto no considera la motivación como un elemento obligatorio en los indultos parciales. Lo fue hasta 1988, pero desapareció de la ley tras su reforma. No obstante, la Sala, apoyándose en el «espiritu de dicha Ley» —recogido en el preámbuloy en el artículo 9.3 CE, anuló el indulto por no dar razones de justicia, equidad o utilidad social para su concesión.

KEY WORDS: Reprieve, prerogative of mercy, motivation, reasons of justice, fairness and social utility, probibition of arbitrariness, discretion, gracious act.

Palabras Clave: Indulto, prerrogativa de gracia, motivación, razones de justicia, equidad y utilidad social, interdicción de la arbitrariedad, discrecionalidad, acto graciable.

FECHA DE RECEPCIÓN: 30.06.2014 FECHA DE ACEPTACIÓN: 30.07.2014

56 Continúa diciendo en su voto particular (FJ 4) que a pesar de que la exposición de motivos de la LI de 1870 parezca decir lo contrario, lo cierto es que la reforma de 1988 eliminó la obligatoriedad de motivar los indultos y que por tanto no debió anularse el indulto sin plantear cuestión de inconstitucionalidad, por implicar una violación del art. 9.3 CE. «Puesto que una decisión del Gobierno que debe ajustarse a la ley, cual es el derecho de gracia, es prácticamente imposible decidir si ha incurrido en arbitrariedad cuando no está motivada. Planteamiento de cuestión de inconstitucionalidad que permitirá, además, esclarecer la doctrina constitucional en relación con el derecho de gracia (...) que no resulta clara». 